\title{
Equity in the utilzation of healthcare services in India: evidence from National Sample Survey
}

\section{Soumitra Ghosh*}

\section{Abstract}

Background: The pursuit of equity in health and healthcare has been the key feature of health policy in India. However, despite the policy significance, the volume of literature available on this issue is scarce. Therefore, this paper is an attempt to examine the horizontal inequities in healthcare utilization, consisting of outpatient and inpatient care in 15 major states and north-eastern region of India.

Methods: Cross-sectional data were taken from the National Sample Survey Organization (NSSO) 60th round (2004), the survey on 'morbidity and healthcare. While outpatient care was assessed using the probability of outpatient visit 15 days prior to the survey date, the indicators of inpatient care utilization were based on the following variables: the probability of hospital admission and length of stay in hospital over a 12-month period. All these measures of healthcare utilization were standardized for need differences and controlled for socio-economic factors. Need standardized concentration indices were used to measure interstate and intrastate income-related inequities in healthcare utilization.

Results: Absolute inequalities were found between states in the proportion of the population reporting a visit to an outpatient provider, in the range of $4.42 \%$ to $21.72 \%$. Similarly, inpatient care varied from $1 \%$ to $10 \%$. The magnitude of inequity for both outpatient and inpatient care was pro-rich across rural and urban areas of India and in majority of the states. In fact, in majority of the states, the horizontal inequity across types of curative care was noticeably higher within the rural population than in the urban population. The analysis demonstrated that high per capita government health spending was significantly associated with low inequity in utilization of inpatient care.

Conclusion: The study concludes that it would be necessary to address the prevailing inequities in healthcare by substantially scaling up the public spending on health, and achieving effective universal coverage of healthcare in India.

Keywords: Horizontal Inequity, Healthcare Utilization, Outpatient Care, Inpatient Care, States, India Copyright: @ 2014 by Kerman University of Medical Sciences

Citation: Ghosh S. Equity in the utilzation of healthcare services in India: evidence from National Sample Survey. Int J Health Policy Manag 2014; 2: 29-38. doi: 10.15171/ijhpm.2014.06
Article History:

Received: 30 October 2013

Accepted: 26 December 2013

ePublished: 6 January 2014

\section{Correspondence to:}

Soumitra Ghosh

Email: soumitra@tiss.edu

\section{Background}

The pursuit of equity in health and healthcare has been the key feature of health policy in India, with the commitment to improve the access to quality healthcare by the poor and disadvantaged. This has been reiterated in almost all policy documents related to health, starting from 'Bhore Committee', 1946 to the latest 'Universal Healthcare Bill', 2009 (1,2). According to these health policy documents, health systems in majority of states in India work toward eliminating the barriers in healthcare utilization and aim to achieve equitable access to healthcare, which is often interpreted as that a person, in equal need of medical care, who receives the equivalent treatment irrespective of his/her income or socio-economic status. To realize this goal, it is imperative to make a systematic assessment of prevailing inequity in utilization of healthcare services which would provide guidance in identifying the points of policy intervention that can reduce the inequity in access to healthcare, a task that has so far not received serious attention both from academia and policy makers.

Despite the policy significance, the volume of literature on this important topic is scarce in the Indian context. Nevertheless, studies on equity in healthcare in Low-and Middle-Income Countries (LMICs) have been reviewed below. Recent evidences suggest that many of these countries have reduced inequities in healthcare use by increasing access to healthcare. For example, in China, inequities in utilization of outpatient and inpatient care have declined significantly in the recent years due to the increased insurance coverage and primary healthcare (3). Chile is another instance, where the health system has become more equitable after the country adopted the 'health guarantee' approach which insured the right of the Chilean people to receive healthcare for majority of the disease conditions (4). Thailand, the first non-OECD country to embrace Universal Health Coverage (UHC) has also shown remarkable improvements with regards to inequality in outpatient care use, though the use of hospital care became more concentrated among the better off between 2001 and 2005 (5). Contrary to this, there are also countries still lagging behind in terms of achieving equity in healthcare utilization. Son (6) found that Philippines with its near universal health insurance coverage, rather experienced a rise in inequity in utilization of health services during the decade 1998 to 2007. Moreover, Mills et al. (7) noted that in South Africa, Ghana, and Tanzania the distribution of healthcare service benefits favored richer people, although the burden of illness was greater for the low-income people. India is no exception. Baru et al. (8) observed that not

${ }^{*}$ Centre for Health Policy, Planning and Management, School of Health Systems Studies, Tata Institute of Social Sciences (TISS), Mumbai, India 
only inequities in access to healthcare persist but have widened across states. Another study which focused on maternal and child health services found that utilization remained pro-rich in India (9).

However, little is known regarding income-related inequalities and inter and intra-state variation in horizontal inequities in healthcare utilization in India. The contribution of this paper is that it takes into account the need differences and controls for other socio-economic factors that affect utilization of curative care. Further, it aims to assess to what extent the healthcare systems of major states and north-eastern region of India have achieved the goal of horizontal equity, i.e. equal access to healthcare for equal needs irrespective of income. Notably, the health economics literature suggests the use of 'utilization' instead of 'access' for understanding the equity in healthcare as this would provide better insights into the factors responsible for inequity in healthcare use $(10,11)$. To show the horizontal inequities in healthcare, I focus on utilization of outpatient and inpatient care.

The remainder of the paper is structured as follows: The next section provides the description of data, and some of its salient features. Section III discusses the estimation techniques and variables used for analysis. Section IV presents the results of the data and finally it ends with a discussion and the concluding note in Section V.

\section{Data}

Cross-sectional data were taken from the National Sample Survey Organization (NSSO) 60th round (2004), the survey on 'morbidity and healthcare. This survey was both nationally and state representative. It collected information on individual and household socio-economic backgrounds, ailments, utilization of healthcare services provided by public and private sectors, and out-of-pocket health payments. The sampling design was stratified in two stages with census villages and urban blocks as the First Stage Units (FSUs) for the rural and urban areas, respectively, and households as the Second Stage Units (SSUs). The survey period, January-June 2004, comprised two subrounds of three months each. The rural and urban samples of FSUs were drawn independently with two sub-samples, and equal numbers of FSUs of each sub-sample were allocated for the two sub-rounds to insure an equal spread of FSUs sample over the entire study period. Table 1 shows that the survey covered 47302 rural and 26566 urban households. It also included responses from 250775 rural and 132563 urban individuals of those households covered in the survey.

\section{Methods}

Measurement of equity

Equity in healthcare utilization is often interpreted as persons in equal need of medical care, who receives the equivalent treatment, irrespective of his/her household income or socioeconomic status. Therefore, according to the principle of

Table 1. Sample size

\begin{tabular}{lccc}
\hline & Rural & Urban & Total \\
\hline Households & 47302 & 26566 & 73868 \\
Individuals & 250775 & 132563 & 383338 \\
\hline
\end{tabular}

horizontal equity, the measure for comparison among the states is inequality in healthcare by income that remains after standardization for healthcare need differences $(12,13)$. Nonetheless, need is mostly intractable in large scale surveys and therefore, quantification remains a major challenge $(14,15)$. The perception of health and disease varies according to culture and socio-economic backgrounds and hence, the researchers have often relied on demographic characteristics and health indicators for standardization of healthcare need, while controlling for non-need variables (16-18).

Therefore, in this study, I utilized the available information on healthcare need and other need-related characteristics to estimate the need-standardized healthcare utilization. Table 2 displays the descriptions of variables selected for quantifying inequity in healthcare. To measure the healthcare utilization, it was broken down into two parts: outpatient and inpatient care. The outpatient care rate was calculated by dividing the total number of people reporting a visit to a formal provider for outpatient care in the last 15 days prior to the survey date by the total sample population. The item in the questionnaire read as follows "Have you consulted any formal healthcare provider in the event of an illness?" In performing the analysis of outpatient care, cases who were reported to be hospitalized during the above-mentioned period were not considered.

However, the measurement of inpatient care utilization was based on two indicators, the annual hospitalization rate which was the probability of hospitalization during the past one year, and the average length of hospital stay. It may be noted that unlike outpatient care, for standardization of inpatient care, 'self-reported health status' could not be used as NSSO did not capture the need for inpatient care in the survey. But while assessing the need standardized mean length of stay, reported disease for hospitalization was used as a proxy of disease severity. The statistics of these variables including the need and control variables are summarized in Table 2. As Table 2 shows, the age structure of rural population was relatively younger than the urban population. The percentage of population reporting illness in the past two weeks was higher (9.95\%) amongst the urban residents than their rural counterparts $(8.82 \%)$. The distribution of diseases among the hospitalized individuals suggests that the burden of communicable diseases was very high in both rural and urban populations. However, of those hospitalized, more people had suffered from communicable diseases in rural areas (62\%) than in urban areas (58\%). On the other hand, the prevalence of non-communicable diseases amongst the hospitalized was higher in urban than in rural areas. Interestingly, the average length of stay was greater in rural areas (9.5 days) compared to urban areas (8.6 days).

The control variables in quantifying the standardized healthcare utilization included marital status, social group, education, employment, income which was proxied by 'per capita monthly household consumption expenditure', health insurance, and region. The penetration of health insurance was very small; while only $0.36 \%$ of the rural residents were enrolled under any health insurance plan, in urban areas the coverage was relatively better (3.13\%). The per capita monthly household consumption expenditure of rural population (Rs. 710; 12 US dollars) was substantially lower compared to their urban counterparts (Rs. 1322; 22 US dollars). Following the estimation of needstandardized healthcare use, concentration index was calculated to measure the magnitude of inequity. These are described in

30 | International Journal of Health Policy and Management, 2014, 2(1), 29-38 


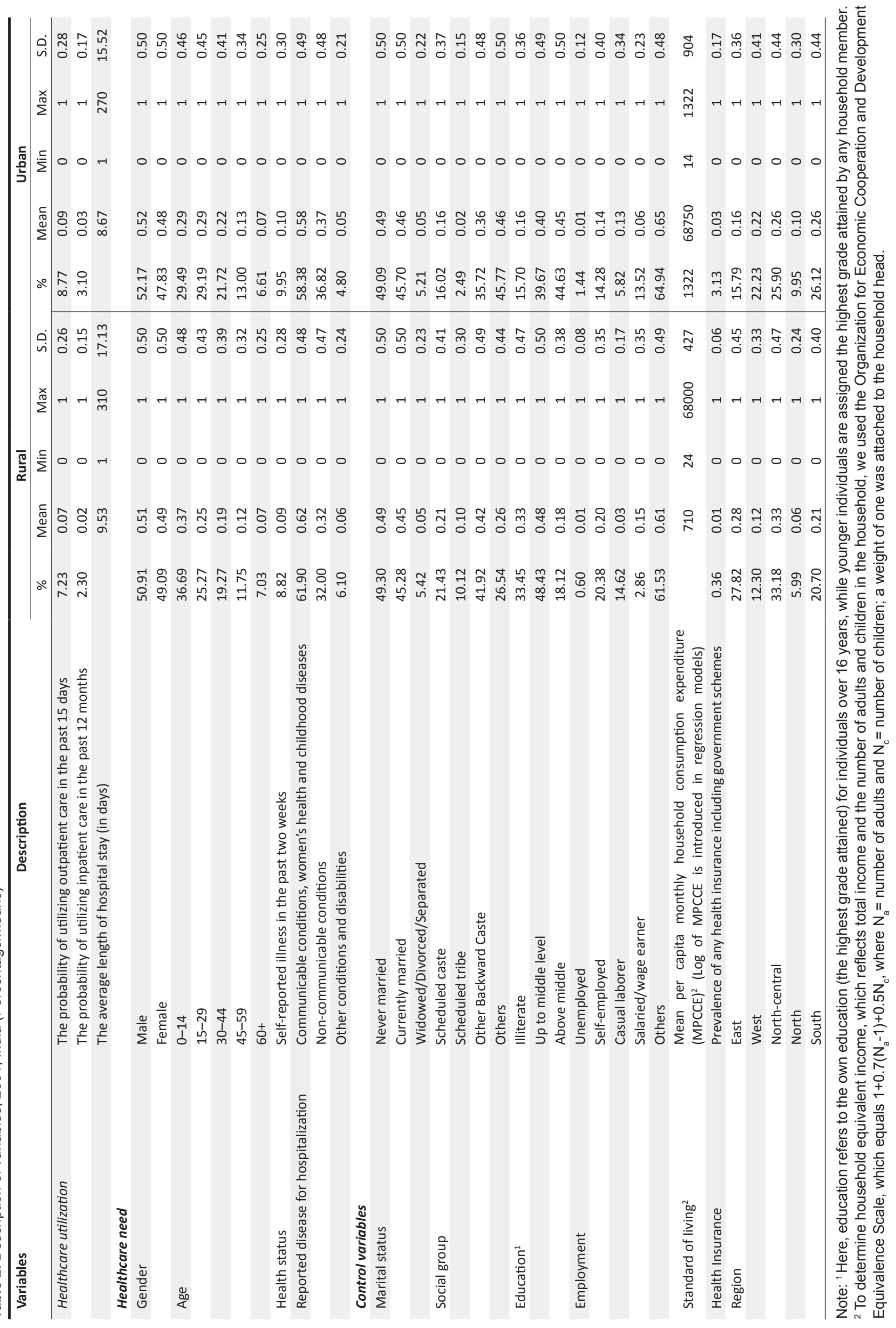


the measurement details below.

\section{Measurement of horizontal inequity in healthcare utilization}

The magnitude of horizontal inequity in healthcare utilization was measured by using the standardized healthcare utilization rate. Since the variable healthcare use is typically non-negative integer which counts with large proportions of observations with no utilization, it would seem proper to use non-parametric models to estimate the need-standardized healthcare. However, evidences demonstrate that the inequity results vary very little when non-linear models (e.g. double-hurdle models) are used instead of Ordinary Least Squares (OLS) $(13,19,20)$. Hence, in this study, a linear regression equation was used to standardize the healthcare utilization. A brief description of the equations used for standardization, and the method of calculating the concentration index used for analyses are presented below [For details see: (21)]. The regression equation was represented by:

$y_{i}=\alpha+\Sigma_{j} \beta_{j} \chi_{j i}+\Sigma_{k} Y_{k} Z_{k i}+\epsilon_{i}$

where $y_{i}$ was healthcare utilization rate; $i$ denoted the individual; and $\alpha, \beta$, and $\gamma$ were parameter vectors. The $x_{i}$ were confounding variables such as age, gender, and self-reported health status which needed to be standardized; and the $Z_{k}$ were nonconfounding variables such as social group, region, income etc. which were included not to be standardized but controlled in order to estimate partial correlations with the confounding variables $(22,23)$. OLS parameter estimates $\left(\hat{\alpha}, \hat{\beta}_{j}, \hat{\gamma}_{k}\right)$, individual values of the confounding variables $\left(x_{j i}\right)$, and sample means of the non-confounding variables $\left(\bar{Z}_{k}\right)$ were then used to obtain the predicted, or "x-expected," values of healthcare utilization $\hat{y}_{i^{x}}$.

Estimates of indirectly standardized health, and $\hat{y}_{i^{i s}}$ were then obtained by the difference between the actual and $\mathrm{x}$-expected health, plus the overall sample mean $(\bar{y})$ :

$\hat{y}_{i^{i s}}=y_{i}-\hat{y}_{i^{x}}+\bar{y}$

The distribution of $\hat{y}_{i^{i s}}$ (e.g. across income) can be interpreted as the distribution of health that would be expected to be observed, irrespective of differences in the distribution of the $x$ 's across income. Following this, the Health Inequity (HI) index was calculated by computing the concentration index with the following formula given below (15).

$$
2 \sigma_{r}^{2}\left(\begin{array}{c}
h i \\
\mu
\end{array}\right)=\alpha+\beta r_{i}+\varepsilon_{i}
$$

Where $h_{i}$ was the standardized healthcare utilization rate; $\mu$ was its mean; $r_{i}=i / \mathrm{N}$ was the fractional rank of the individual; $i$ was the distribution of monthly per capita household consumption expenditure, with $i=1$ for the poorest and $i=\mathrm{N}$ for the richest; and $\sigma_{r}^{2}$ was the variance of the fractional rank. The OLS estimate of $\beta$ was an estimate of the concentration index. A zero value of $\mathrm{HI}$ index indicated that horizontal equity existed, i.e. the proportionality between use of medical care and need for healthcare was the same, irrespective of household income. When positive, the index indicated pro-rich inequity and when negative, it indicated pro-poor inequity. In other words, inequity was captured here by the difference between inequality in utilization and inequality in need; if inequality in utilization was less than inequality in need, then the measure of inequity was positive indicating that the inequity favored the non-poors (20).

\section{Results}

Inequity in healthcare utilization

The objective of this section is to quantify the magnitude of income-related inequity in outpatient and inpatient care utilization across states, rural, and urban areas. The outpatient care rate was slightly higher in urban areas $(9 \%)$ than in rural areas $(7 \%)$ at the national level $(P<0.01$; Figure 1$)$. However, there were significant absolute inequalities across and within the states. The outpatient care rate of only three states namely Kerala (22\%), Punjab (12\%), and West Bengal (10\%) were higher than 10\%, with Bihar (4.42\%), Rajasthan (5.40\%), and Karnataka (5.01\%) being amongst the lowest.

In many states, the difference in outpatient care utilization rate between the rural and urban areas was noteworthy. West Bengal was one such example where the rural areas had the outpatient care rate of $9.10 \%$. On the other hand, urban areas had the outpatient care rate of $12.95 \%$ with the difference of $3.85 \%$

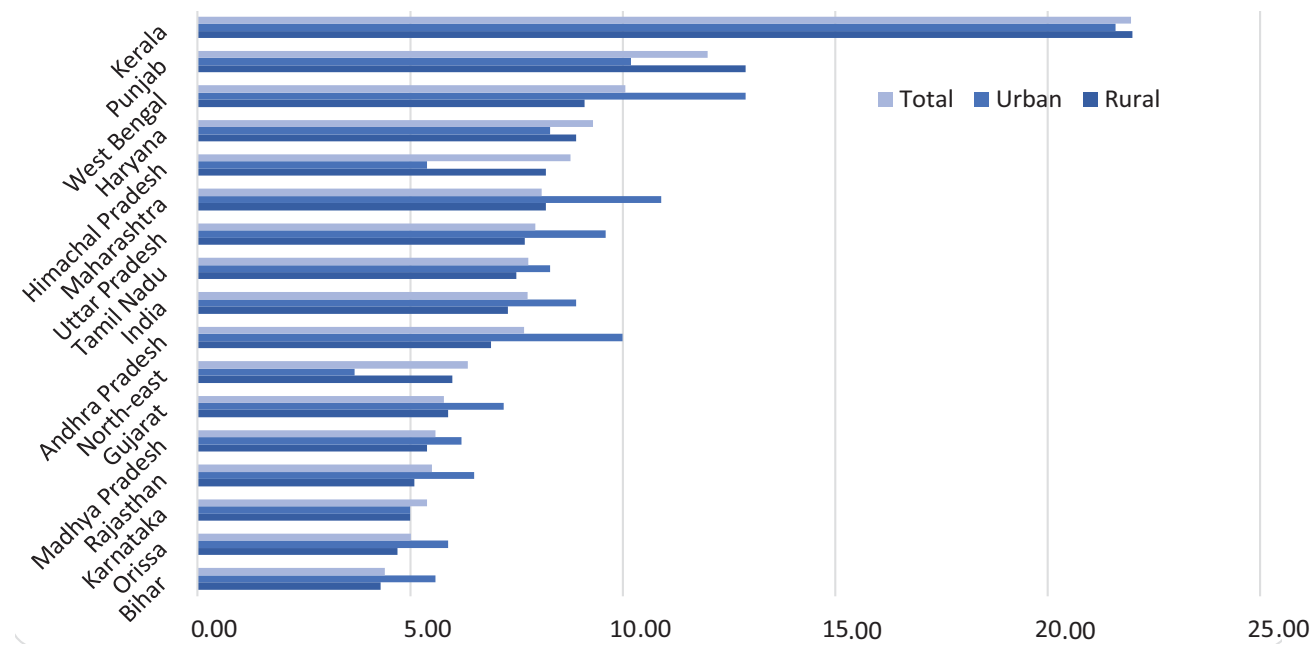

Figure 1. Outpatient care rate (in percent) by place of residence in 15 major states, NE region and India in the last 15 days prior to the survey date, 2004

32 | International Journal of Health Policy and Management, 2014, 2(1), 29-38 
points $(P<0.01)$. Similarly, in two other states, Maharashtra and Andhra Pradesh, the outpatient care rate in urban areas crossed the $10 \%$ mark, reasonably fair amount of utilization gave their epidemiological and demographic profile. But rural areas lagged far behind in terms of outpatient care utilization, though the healthcare need of the rural population could be higher than their urban counterparts. Furthermore, the outpatient care was more used in urban areas than in rural areas in all the states except Punjab, Himachal Pradesh, Haryana, and Northeast region.

In case of inpatient care, the national average was $2.40 \%$ (Figure 2 ). The rural-urban differential was substantial, with the hospitalization rate of $2.20 \%$ among the rural population and $3.10 \%$ in urban population $(P<0.01)$. The national average also made the huge inter-state inequalities in annual hospitalization rate. It varied in the range of $1 \%$ to $10 \%$. The probability of hospital admission was the highest in Kerala (10\%), followed by Tamil Nadu (4\%), and Maharashtra (3\%); but it was the lowest in Bihar (1\%), Uttar Pradesh (1\%), and North-east (1\%). All states, except Kerala, showed higher hospitalization rate in urban areas than in rural ones.

\section{Inter-state differences in income-related inequity in outpatient} care use

In this section, the inter-state, intra-state and rural-urban comparisons of the results of horizontal inequities in needstandardized outpatient care by income are presented. Figure 3 depicts the magnitude of income-related inequity for the probability of visiting an outpatient provider after controlling the need and non-need factors. Adjusting for age, gender and health status and other non-need factors, the results revealed that the magnitude of inequity for outpatient care contact was pro-rich across rural and urban areas of India and some of the states.

The extent of inequity in outpatient care across rural and urban areas differed from one state to the other. However, in majority of the states including India, a noticeable pattern was that although the utilization of outpatient care was tilted in favor of the rich irrespective of the place of residence, the magnitude of inequity was lesser in urban areas compared to rural areas. This implied that the access to outpatient care for the poor seemed to be relatively better in the urban areas than in rural areas.

Interestingly, states such as Punjab, Kerala, and North-east region achieved nearly horizontal equity in outpatient care utilization in rural and urban areas. It does not necessarily imply that the distribution of outpatient care was equitable in these states because of the fact that a significant proportion of poor people probably did not report any health problems, primarily because of the low health ideals compared to their wealthy counterparts. But given the fact that differences in actual and perceived health need and health seeking behavior existed across income groups in all these states, it could be inferred that the poor had relatively better access to outpatient care in these high-and middle-income states.

This could plausibly be explained by the following reasons. The per capita government spending on healthcare has been relatively higher in Punjab and Kerala compared to other states (24). Furthermore, Kerala is known for having better healthcare infrastructure than the rest of India. Also, since Punjab and Kerala are economically advanced states, people are likely to have relatively greater ability to pay for outpatient care. In case of North-east region, the states of this region always had better healthcare infrastructure at the primary level than majority of the states in India (25).

\section{Inter-state differences in income-related inequity in inpatient care} use

In this section, the inter-state comparisons of the results of horizontal inequities in need-standardized inpatient care use by income are presented. Total inpatient use was disaggregated into the probability of hospital admission and mean length of stay in hospital (conditional use i.e. given that the person spent at least a night in the hospital). Both these measures of inpatient care were assessed and quantified across all states.

\section{Inequities in the probability of hospitalization}

The observed distribution of hospital admission was pro-rich across rural and urban populations, as indicated by positive $\mathrm{HI}$ index values at all-India level and most of the selected states (Figure 4). This implied that in majority of the states, the high income groups used inpatient care more than the lower-income groups. However, the smaller horizontal inequity in the urban

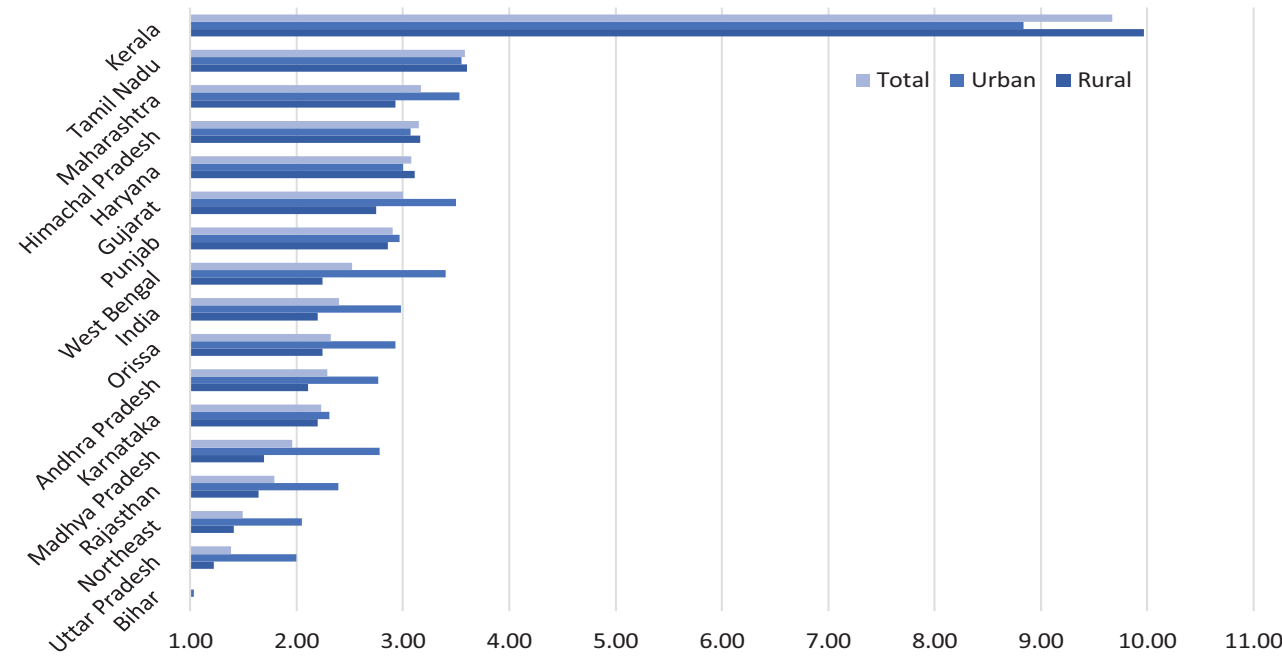

Figure 2. Hospitalization rate (in percent) by place of residence in 15 major states, NE region and India during the period of 12 months preceding the survey date, 2004 


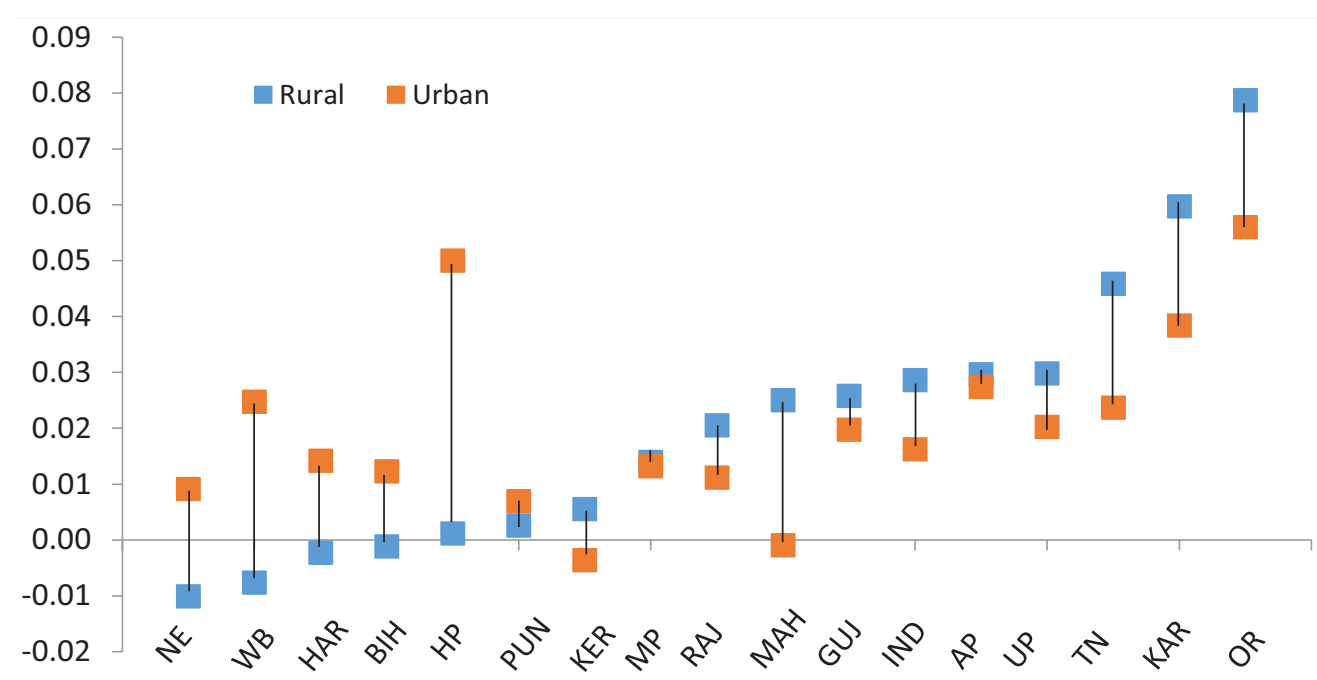

Figure 3. Horizontal inequity indices for the probability of visiting an outpatient provider in 15 major states, NE region and India, 2004

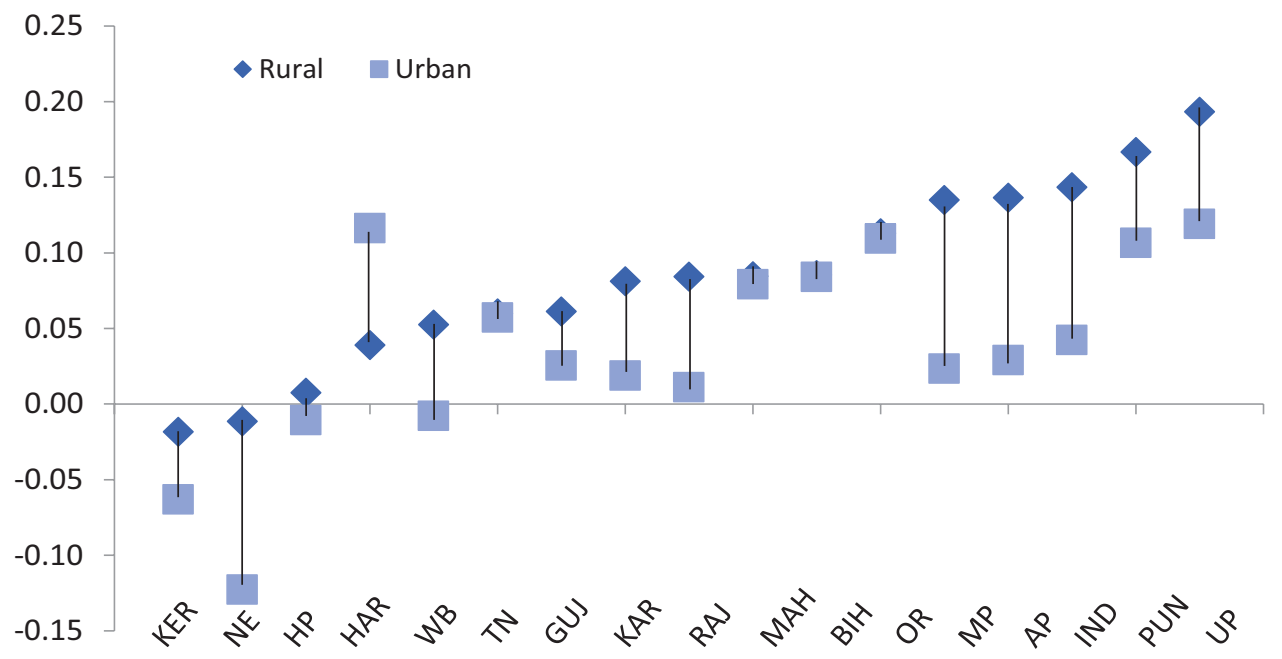

Figure 4. Horizontal inequity indices for hospital admission in 15 major states, NE region and India, 2004

areas signified more equitable inpatient care use within urban population compared to rural population.

Kerala and Himachal Pradesh which have better developed services are the only states in which the distribution was propoor across locales. While horizontal equity principle was almost achieved in the rural parts of North-east region, propoor inequity was observed in the urban areas $(\mathrm{HI}=-0.01)$. Expectedly, Uttar Pradesh demonstrated the highest pro-rich horizontal inequity in both rural and urban areas. While the poor might have been forced to forgo healthcare due to insufficient public healthcare infrastructure, the high healthcare utilization from private providers by the rich might be contributed to the prevailing high inequities in Uttar Pradesh.

The examination of the relationship between the income inequity in hospital admission and the level of per capita public health spending by states showed an inverse association (Figure 5). However, the gradient was steeper in urban than in rural areas, indicating that this relationship was stronger and statistically significant in the former (correlation $=-0.60$, coefficient $=95 \% ; \mathrm{CI}=-0.85$ to $-0.13 ; P<0.05)$ than in the later (correlation $=-0.40$, coefficient $=95 \%$; $C I=-0.76$ to 0.14 ; $P<0.05)$. This means that as the per capita public spending on health increases, the horizontal inequity in utilization of inpatient care decreases, more so for the urban population. This could be because of the fact that in India, the poor still heavily depend on public facilities for availing inpatient care services (26). Moreover, as in most of the states, the public inpatient facilities are disproportionately located in the urban areas, the high level of public health spending would have an equity enhancing effect on inpatient care utilization especially among the urban population.

\section{Inequities in Conditional Mean Length of Stay (LOS)}

The distributional pattern for conditional mean length of stay in hospital seemed to be different from the probability of hospitalization (Figure 6). The need-standardized distributions of 'mean length of stay in hospital' were pro-poor across locales at the all-India level. Interestingly, in India and in majority of the states, urban areas showed significantly greater inequity indices for mean length of stay, favoring the poor. This might be explained by the fact that in urban areas, rich can afford to get quality healthcare whereas the poor can not, implying that they would have to stay longer than their richer counterparts. On the other hand, in many states, particularly in rural areas, 
the better-off stayed for a longer time in hospital, though the health conditions of the poor were expected to be poorer than the rich people. This situation emerged as a result of the high out-of-pocket health payments associated with the utilization of inpatient care in those states.

\section{Discussion and Conclusion}

The study examined horizontal inequities in healthcare utilization across rural and urban populations in 15 major states, North-east region and India. I also investigated the relationship between horizontal inequity in hospital admission and per capita public spending on health. The current levels of healthcare utilization was abysmally low in most of the states and in some states where healthcare utilization was relatively better, intra-state rural-urban differences were substantial. Interestingly, all indicators of healthcare utilization showed higher utilization rates amongst the urban population whereas the rural population required greater medical attention. Furthermore, results clearly suggest that utilization of both outpatient care and inpatient care was associated with income at the country level. In other words, people with similar healthcare needs continue to receive varying levels of healthcare depending on their income i.e. the ability to pay, which is consistent with findings from other studies conducted in LMICs $(5,6,16,27)$.

The income-related differences in outpatient care utilization varied considerably from state to state. Only two states-Punjab, Kerala, and North-east region achieved horizontal equity in outpatient care utilization. Importantly, in a large number of states, while both rural and urban areas showed pro-rich inequity, the utilization of outpatient care was less inequitable in urban areas than in rural areas.

Like outpatient care, the distributions of different components of inpatient care showed some interesting patterns. In majority of the states, the distributions of hospital admission were considerably concentrated amongst the rich across locales but the extent of inequity was much greater within the rural areas than in urban areas. Importantly, the distribution of 'average length of stay in hospital' seemed to favor the poor significantly in most of the states, especially in the urban areas. The following could be the explanations for these observed patterns in inpatient care utilization.

It may be noted that the availability of both private and public healthcare services is highly skewed toward the urban areas in India. In fact, urban population who make up only $28 \%$ of India's

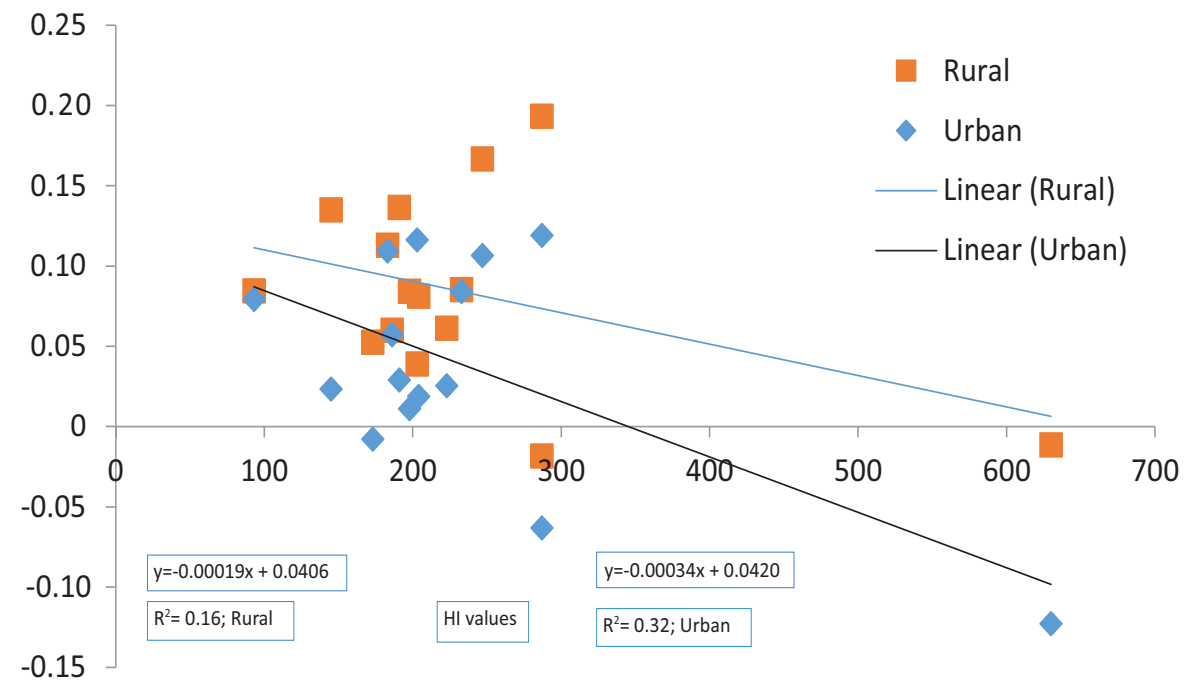

Figure 5. Relationship between per capita public health spending and inequity in hospital admission Note: Spending data was used from CMIE reports (24). North-east region is not included in the analysis due to non-availability of disaggregated public expenditure data.

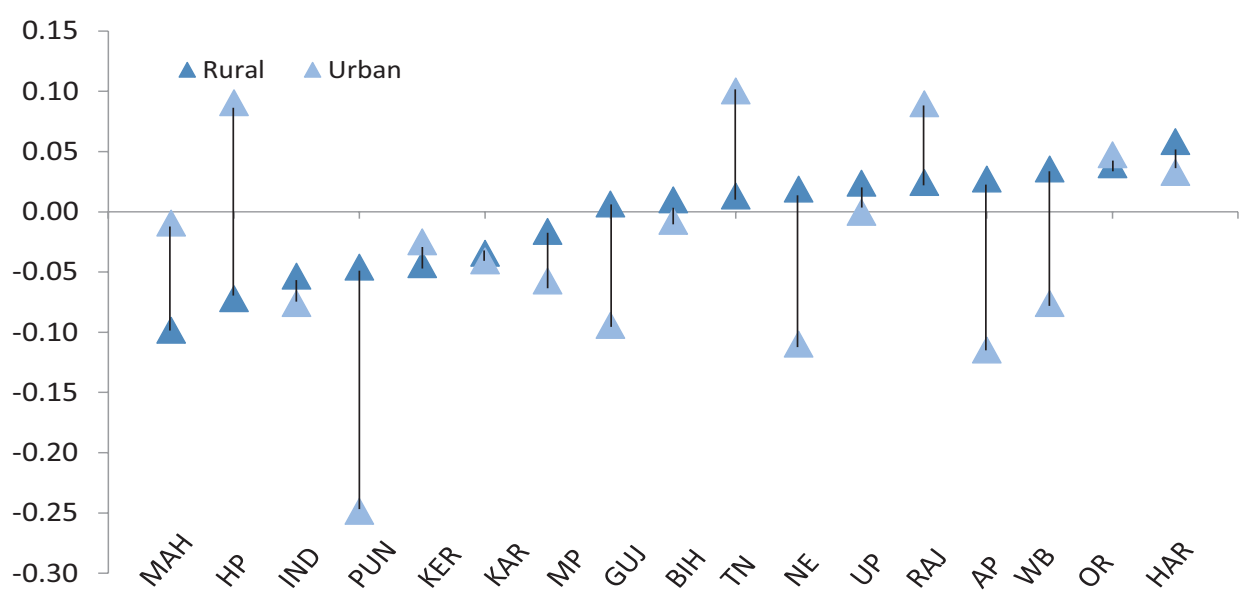

Figure 6. Horizontal inequity indices for hospital days in 15 major states, NE region and India, 2004 
population have access to $66 \%$ of country's total hospital beds, whereas the proportion of beds available for the remaining $72 \%$ population in rural areas stands at $34 \%$ (28). This concentration of services in the urban areas may have led to a more equitable distribution of inpatient care utilization in urban areas vis-à-vis rural areas.

However, the quality of care varied significantly across public and private hospitals in urban areas (29); and it appeared that amongst the urban poor, those who were able to seek inpatient care ended up receiving relatively inferior quality of care compared to their better-off counterparts as reflected in their longer duration of stay in the hospital. On the other hand, due to the insufficient availability of hospitals in the rural areas, the choice for accessing inpatient care was very limited for the rural residents, and as the available services were not affordable and accessible to the poor, the rich spent more nights in the hospital than the poor.

The analysis of the relationship between horizontal inequity in hospital admission and per capita public spending on health revealed that states with higher per capita public spending on health, on average, had a lower level of inequity in inpatient rate. Clearly, the higher spending on healthcare by the state governments increases the ability of the public health facilities to cope up with the increasing demand for healthcare and thereby improves the utilization of inpatient care by the poor. This is in line with the findings of other studies $(30,31)$. However, states such as Punjab and Andhra Pradesh even with relatively higher level of public spending showed higher level of pro-rich inequity in inpatient care.

The findings of the study have profound policy implications. In majority of the states, the horizontal inequity in both outpatient care and hospitalization was significantly greater within rural population than in urban population. This highlights the need for greater attention to meet the healthcare needs of the rural and poor populations.

Of late, there have been some major changes in the health policy and program domain in India. The National Rural Health Mission (NRHM) was launched in 2005 to strengthen the public health systems by addressing some of the key issues such as inadequate financing, shortage of human resources, infrastructure, and quality of care which were plaguing the public sector for long (2). NRHM also envisaged to engage with the private sector to contribute to the provision of quality healthcare to the poor and marginalized sections; however, the role of the private sector and its regulation is not clearly delineated (7). Although NRHM covers the entire country, it focuses on less developed states and many of the programs are targeted to the disadvantaged groups in those states, as a strategy to reduce the inter-state and intra-state inequities in the availability of health services (7).

In the absence of a systematic evaluation of NRHM, it will not be possible to make any conclusive inferences about the healthcare equity impacts of this flagship health program (32). However, preliminary evidences from the existing studies on NRHM suggest that the performance of the program varies greatly from state to state. Furthermore, states which were lagging behind in the pre-NRHM period did not show any remarkable improvement (33). Besides, there are concerns such as infrastructure, and availability of logistics but the most pressing issue affecting the delivery of healthcare is the availability of human resources.

In an effort to overcome the dependence on out-of-pocket expenditure and inequities in access to quality healthcare particularly across rich-poor divide, the government of India started a flagship program called Rashtriya Swasthya Bima Yojana (RSBY) in 2008. It is an insurance program that entitles Below Poverty Line (BPL) families secondary level inpatient care up to an annual sum of Rs. 30,000 (500 US dollars). But the review of existing studies point to several challenges with regard to implementation of RSBY.

First, the overall, RSBY uptake has not been very impressive and the enrollment of BPL families varies considerably across states and districts (34-36). Second, the tribal dominated blocks fares very poorly in terms of RSBY enrollment, suggesting that RSBY has not been socially inclusive (37). Third, a preliminary evaluation of RSBY shows that it has achieved limited success in providing financial protection to the poor (38).

Traditionally, target-based approaches have yielded very limited success in providing 'access to healthcare' to the poor and marginalized people. Evidences suggest that the poorest of the poor and socially excluded groups are more likely to be included in a universal health program. The Government of India has made an important announcement in this direction. It has declared that it would like to achieve Universal Health Coverage (UHC) by 2022 (39). A framework has already been laid out on how to implement the program and the piloting is likely to start in some states soon (39). While the recommendation of the high-level expert group on UHC is to provide a comprehensive health package to all citizens, it is not apparent what services are currently available to whom.

Our analysis of healthcare utilization shows that a small proportion of the population is currently covered by curative care. The analysis also revealed that there are substantial inter-state and intra-state disparities and significant inequities in the distribution of these services. In order to address the persistence of inequities in health and healthcare, it would be necessary to insure effective universal healthcare, implying that all population groups with need receive effective coverage.

\section{Limitation of this study}

This study has some limitations. The quality of data on 'selfreported health status' needs to be improved. The health status of individuals was assessed by using the information whether a person reported an illness in the past 15 days. In areas of poor healthcare access, the morbidity level may actually represent healthcare utilization levels, rather than the actual health status $(40,41)$. Therefore, the results are subject to the limits of selfreported morbidities.

\section{Ethical issues}

Not applicable.

\section{Competing interests}

The author declares that he has no competing interests.

Author's contribution

$S G$ is the single author of the manuscript. 


\section{References}

1. Bhore J, Amesur R, Banerjee A. Report of the Health Survey and Development Committee. Delhi: Government of India; 1946.

2. Government of India. Draft National Health Bill. New Delhi: Ministry of Health and Family Welfare; 2009.

3. Zhou Z, Su Y, Gao J, Campbell B, Zhu Z, Xu L, et al. Assessing equity of healthcare utilization in rural China: results from nationally representative surveys from 1993 to 2008. Int J Equity Health 2013; $12: 34$

4. Frenz P, Delgado I, Kaufman JS, Harper S. Achieving effective universal health coverage with equity: evidence from Chile. Health Policy Plan 2013; forthcoming.

5. Yiengprugsawan V, Carmichael G, Lim LY, Seubsman S, Sleigh A. Explanation of inequality in utilisation of ambulatory care before and after universal health insurance in Thailand. Health Policy Plan 2011; 26: 105-14.

6. Son $\mathrm{HH}$. Equity in health and healthcare in the Philippines [internet]. 2009. Available from: http://www.adb.org/publications/ equity-health-and-health-care-philippines

7. Mills A, Ataguba JE, Akazili J, Borghi J, Garshong B, Makawia S, et al. Equity in financing and use of healthcare in South Africa, Ghana and Tanzania: Implications for Paths to Universal Health Coverage. Lancet 2012; 380: 126-33.

8. Baru R, Acharya A, Acharya S, Kumar AK, Nagaraj K. Inequities in access to health services in India: caste, class and region. Econ Polit Wkly 2010; 45: 49-58.

9. Balrajan Y, Selvaraj S, Subramanian S V. Healthcare and Equity in India. Lancet 2011; 377: 505-15

10. Culyer AJ, van Doorslaer E, Wagstaff A. Access, Utilisation and Equity: A Further Comment. J Health Econ 1992; 11: 207-10.

11. Culyer AJ, van Doorslaer E, Wagstaff A. Utilisation as a Measure of Equity by Mooney, Hall, Donaldson and Gerard. J Health Econ 1992; 11: 93-8.

12. Wagstaff $A$, van Doorslaer E. Equity in healthcare finance and delivery. In: Culyer AJ, Newhouse JP, editors. Handbook of Health Economics. Amsterdam: Elsevier; 2000. p.1803-62.

13. Wagstaff A, van Doorslaer E. Measuring and Testing for Inequity in the Delivery of Healthcare. J Hum Resour 2000; 35: 716-33.

14. Culyer AJ. Need: the idea won't do--but we still need it. Soc Sci Med 1995; 40: 727-30.

15. Culyer AJ, Wagstaff A. Equity and equality in health and healthcare. $J$ Health Econ 1993; 12: 431-57.

16. Kim Y, Kwon S, Xu K. Has Income-related Inequity in Healthcare Utilization and Expenditures Been Improved? Evidence From the Korean National Health and Nutrition Examination Survey of 2005 and 2010. J Prev Med Public Health 2013; 46: 237-48.

17. Zhao $Y$, Zhang Y, Tang J, Wang L, Wan Q, Tao S. Case Study on Horizontal Equity in Health Services Utilization is a component of Equity Research in Health Areas. Chinese Health Economics 2005; 24: 5-7.

18. O'Donnell O, van Doorslaer E, Wagstaff A, Lindelow M. Analyzing Health Equity Using Household Survey Data: a Guide to Techniques and their Implementation. Washington, DC: World Bank; 2008

19. van Doorslaer E, Masseria C, OECD Health Equity Research Group. Income-Related Inequality in the Use of Medical Care in 21 OECD Countries [internet]. 2004. Available from: http://www.oecd. org/els/health-systems/31743034.pdf

20. van Doorslaer E, Wagstaff $A$, van der Burg $H$, Christiansen $T$, De Graeve D, Duchesne I, et al. Equity in the delivery of healthcare in Europe and the US. J Health Econ 2000; 19: 553-84.

21. O'Donnell O, Doorslaer EV, Rannan-Eliya RP, Somanathan A, Adhikari SR, Har-bianto D, et al. The Incidence of Public Spending on Healthcare: Comparative Evidence from Asia. World Bank Econ Rev 2007; 21: 93-123.

22. Gravelle H. Measuring income related inequality in health: standardisation and the partial concentration index. Health Econ 2003; 12: 803-19.

23. Schokkaert E, Dhaene G, Voorde VD. Risk adjustment and the trade-off between efficiency and risk selection: an application of the theory of fair compensation. Health Econ 1998; 7: 465-80.

24. Centre for Monitoring Indian Economy (CMIE) (various years). Database on national income statistics [internet]. Available from: http://www.cmie.com/

25. Saikia D, Das K. Rural health infrastructures in North-east India [internet]. 2012. Available from: http://mpra.ub.uni-muenchen. de/41859/

26. Mahal A, Yazbeck AS, Peters DH, Ramana GNV. The Poor and Health Services Use in India. Washington, DC: World Bank; 2001.

27. Odeyemi IA, Nixon J. Assessing equity in healthcare through national health insurance schemes of Nigeria and Ghana: A review based comparative analysis. Int J Equity Health 2013; 12: 9.

28. IMS Institute for Health Informatics. Understanding healthcare access in India: what is the current state? [internet]. 2013. Available from: http://www.imshealth.com/deployedfiles/imshealth/ Global/Content/Corporate/IMS\%20Institute/India/Understanding_ Healthcare Access in India.pdf

29. Levesque JF, Haddad S, Narayana D, Fournier P. Outpatient care utilisation in urban Kerala, India. Health Policy Plan 2006; 21: 289-301

30. Prinja S, Kumar MI, Pinto AD, Jan S, Kumar R. Equity in hospital services utilisation in India. Econ Polit Wkly 2013; 48: 52-8.

31. Chuma J, Maina T, Ataguba J. Does the distribution of healthcare benefits in Kenya meet the principles of universal coverage? BMC Public Health 2012; 12: 20

32. Reddy KS, Patel V, Jha P, Paul VK, Shiva Kumar AK, Dandona L. Towards achievement of universal healthcare in India by 2020: a call to action. Lancet 2011; 6736: 61960-5.

33. Gill K. A Primary Evaluation of service delivery under the National Rural Health Mission (NRHM): findings from a study in Andhra Pradesh, Uttar Pradesh, Bihar and Rajasthan. Working paper 1. New Delhi: Planning Commission of India; 2009.

34. Ghosh S, Thakur H. Social Exclusion and Rashtriya Swasthya Bima Yojana in Maharashtra: A Case Study. Mumbai: Tata Institute of Social Sciences; 2013.

35. Sun C. An analysis of RSBY enrolment patterns: Preliminary evidence and lessons from the early experience. In: Palacios R, Das J, Sun C, editors. India's health insurance scheme for the poor: evidence from the early experience of the Rashtriya Swasthya Bima Yojana. New Delhi: Centre for Policy Research; 2011.

36. Narayana D. Review of the Rashtriya Swasthya Bima Yojana. Econ Polit Wkly 2010; 45: 13-8.

37. Rathi P, Mukherji A, Sen G. Rashtriya Swasthya Bima Yojana: Evaluating Utilisation, Roll-out and Perceptions in Amravati District, Maharashtra. Econ Polit Wkly 2012; 47: 57-64.

38. Selvaraj S, Karan A. Why Publicly-Financed Health Insurance Schemes Are Ineffective in Providing Financial Risk Protection. Econ Polit Wkly 2012; 47: 60-8.

39. Government of India. High Level Expert Group Report on Universal Health Coverage, Planning Commission of India. New Delhi: Government of India; 2011.

40. Dilip T R. Understanding levels of morbidity and hospitalisation in Kerala, India. Bull World Health Organ 2002; 80: 746-51.

41. Murray CJL, Chen LC. Understanding morbidity changes. Popul Dev Rev 1992; 18: 481-503. 


\section{Key Messages}

Implications for policy makers

- By enhancing the public health spending, the government can reduce the overall inequity in healthcare utilization and thereby health.

- In order to address the issue of large rural-urban differentials in healthcare utilization, the government needs to make greater financial allocation to meet the healthcare needs of the rural population.

- In light of the evidences that people with lower economic backgrounds underused both outpatient and inpatient care than their richer counterparts, it will be necessary to embed a pro-poor policy bias within the Universal Health Coverage (UHC) framework to achieve equity in healthcare.

- The current curative healthcare utilization indicators together with Health Inequity (HI) indices could help guide to make appropriate decisions on resource allocation to provide curative care to different states and sections of the population and monitor progress toward UHC.

\section{Implications for public}

The study showed that in many states in India, the current rate of healthcare utilization i.e. outpatient visits and use of hospital care is very low, implying that people are not able to obtain these services even though they need them. Moreover, the results clearly revealed the fact that those who are poor and reside in rural areas are actually at a greater disadvantage in terms of healthcare use than their richer and urban counterparts. This causes the inequity in healthcare utilization. But the analysis suggests that states with higher level of public spending on health have experienced relatively lower level of inequities in healthcare utilization. It would be therefore, highly desirable that the government invests more on health to address the prevailing inequities in healthcare. 